\title{
Vaccine Watch
}

\section{A RENAISSANCE FOR HIV VACCINES?}

"The discoveries we have made may overcome the limitations that have long stymied antibody-based HIV vaccine design". This bold claim from Peter Kwong (NIAID News Release, 8 July 2010), one of the lead authors of two papers in Science describing the discovery of three broadly neutralizing human antibodies specific for HIV-1, sums up a new feeling of cautious optimism in the HIV vaccine field, referred to by Wayne Koff of the International AIDS Vaccine Initiative as a 'renaissance' in HIV research (Wall Street Journal, 8 July 2010).

Naturally occurring B cells producing these neutralizing antibodies were isolated from the blood of an HIV-infected long-term non-progressor patient using a molecular probe comprising the invariant CD4-binding site of the gp120 envelope glycoprotein of HIV-1. Two of the antibodies cloned from these cells, VRC01 and VRC02, were shown to neutralize more than $90 \%$ of all known circulating HIV-1 isolates. John Mascola, who also worked on the study, explained that, "The antibodies attach to a virtually unchanging part of the virus, and this explains why they can neutralize such an extraordinary range of HIV strains" (Reuters, 8 July 2010).

By determining the structure of VRC01 bound to HIV-1 the authors have established precisely how this antibody recognizes diverse virus isolates; they hope to use this information to design candidate antigens that will elicit similar antibodies in vaccinated individuals. As Barton Haynes of Duke University explained in simple terms, the researchers have found "a rare patient that has the type of antibodies we would like to induce with a vaccine" and then have used these antibodies to "find out which part of [the HIV-1] envelope the right kind of antibodies should bind to" (abcNews.com, 8 July 2010).

Anthony Fauci, Director of the US National Institute of Allergy and Infectious Diseases (NIAID), which funded the research, told CNN (9 July 2010) that "the potential for a vaccine is here". Gary Nabel, Director of the Vaccine Research Center at the NIAID and one of the study authors told Reuters that he is "more optimistic about an AIDS vaccine at this point in time than ... in the last 10 years", although he cautioned that "We're going to be at this for a while" before this knowledge translates to clinical benefit (Wall Street Journal).

In addition to prophylactic vaccination, these antibodies could be used therapeutically in infected individuals to "get more effective control of the virus and suppress it down to low levels", according to Nabel (abcNews.com). Furthermore, the technique used to find these new antibodies "represents a novel strategy that could be applied to vaccine design for many other infectious diseases" according to Fauci (NIAID News Release).

ORIGINAL RESEARCH PAPERS Wu, X. et al. Rational design of envelope identifies broadly neutralizing human monoclonal antibodies to HIV-1. Science 8 Jul 2010 (doi:10.1126/science.1187659)|Zhou, T. et al. Structural basis for broad and potent neutralization of HIV-1 by antibody VRC01. Science 8 Jul 2010 (doi: 10.1126/ science.1192819) 